\title{
Continuum damage mechanics modeling for fatigue life of elastomeric materials
}

\begin{abstract}
Purpose: The purpose of this paper is to investigate the fatigue behavior of rubber using dumb-bell test specimens under uniaxial loading. Design/methodology/approach: The material used is a vulcanized natural rubber with a formulation typical for engine mounts and an international rubber hardness degree of 60. Fatigue tests are conducted under the displacement controlled condition with a sine waveform of $0.1 \mathrm{~Hz}$ and the load ratio of zero. Findings: In modeling fatigue damage behavior, a continuum damage model is presented based on the function of the strain range under cyclic loading. The Ogden strain energy potential is used to define the constitutive relation of the natural rubber. A good agreement is obtained between fatigue experimental data and theoretical predictions. Originality/value: Fatigue analysis and lifetime evaluation are very important in design to ensure the safety and reliability of rubber components. The design of rubber against fatigue failure is an important topic that must be considered for safety during operation.
\end{abstract}

Keyword: Elastomers; Rubbers; Fatigue; Modelling 